\title{
Bladder Adenocarcinoma
}

National Cancer Institute

\section{Source}

National Cancer Institute. Bladder Adenocarcinoma. NCI Thesaurus. Code C4032.

A rare adenocarcinoma arising from metaplastic bladder epithelium. It is frequently associated with long-standing local irritation. The majority of cases originate from the trigone and the posterior wall of the bladder. 